\section{To Cope or Not to Cope? Characterizing Biology Graduate Teaching Assistant (GTA) Coping with Teaching and Research Anxieties}

\author{
Miranda M. Chen Musgrove, ${ }^{\dagger *}$ Alyssa Cooley, ${ }^{*}$ Olivia Feiten, ${ }^{\S}$ Kate Petrie, ${ }^{\ddagger}$ and \\ Elisabeth E. Schussler $\$$ \\ 'Department of Ecology and Evolutionary Biology, University of Colorado Boulder, Boulder, \\ CO 80309; "Department Psychology and \$Department of Ecology and Evolutionary Biology, \\ University of Tennessee, Knoxville, TN 37996
}

\begin{abstract}
Recent evidence suggests a mental health crisis among graduate students, particularly with regard to anxiety. To manage anxieties, graduate students can employ coping strategies. Coping is an individual's response(s) to external stressors, often with the goal of reducing or tolerating the stress; these strategies are generally considered adaptive or maladaptive. Adaptive coping strategies advance individuals through problems, while maladaptive strategies prevent stressors from being resolved. We previously identified differences between teaching and research anxieties in a sample of biology graduate teaching assistants (GTAs). This study investigated whether coping with these anxieties differed in this population as well. We interviewed 23 biology GTAs twice over one year. Interview data were qualitatively analyzed using Skinner and colleagues' major coping families as categories. Biology GTAs most often used adaptive coping strategies, such as problem solving and information seeking, to manage both teaching and research anxieties. However, other coping strategies were preferentially employed for either teaching or research, suggesting differences in these aspects of graduate student life. Over one year, GTAs reduced the number of coping strategies they employed. Understanding how GTAs cope with teaching and research anxieties may inform the types of support faculty and professional development leaders can provide to graduate students.
\end{abstract}

\section{INTRODUCTION}

Coping is defined as an individual's cognitive and behavioral efforts to manage the specific external and internal demands that are appraised as taxing or exceeding his or her resources (Lazarus and Folkman, 1984; Folkman et al., 1986). As mental health problems such as depression and anxiety pervade academia (Evans et al., 2018; Lashuel, 2020), coping skills are integral for individuals to navigate stressors. This is especially salient among our graduate student population (Nagy et al., 2019; Gin et al., 2021). Graduate students are increasingly likely to report high levels of anxiety, affecting their overall mental health and attrition in graduate programs (Rummell, 2015; Levecque et al., 2017; Evans et al., 2018). Though graduate student mental health issues are starting to be explored in greater depth (Woolston, 2019; Gin et al., 2021), identifying how students cope with various stressors remains in its infancy. The objective of this study was to explore how a set of biology graduate teaching assistants (GTAs) coped with anxieties that were specifically generated by their distinct roles as teachers and as researchers at their university.

Part of a graduate student's socialization into academia is learning how to effectively balance multiple roles: teachers, researchers, students, and employees (Van Maanen, 1976; Austin, 2002, 2003; Golde, 2005; Kajfez and McNair, 2014;
Erika Offerdahl, Monitoring Editor Submitted Aug 20, 2020; Revised Aug 9, 2021 Accepted Aug 17, 2021

CBE Life Sci Educ December 1, 2021 20:ar56 DOI:10.1187/cbe.20-08-0175

*Address correspondence to: Miranda M. Chen Musgrove (miranda.chen (acolorado.edu). (c) 2021 M. M. C. Musgrove et al. CBE-Life Sciences Education @ 2021 The American Society for Cell Biology. This article is distributed by The American Society for Cell Biology under license from the author(s). It is available to the public under an Attribution-Noncommercial-Share Alike 3.0 Unported Creative Commons License (http://creativecommons.org/licenses/ by-nc-sa/3.0).

"ASCB®" and "The American Society for Cell Biology $\bigotimes^{\prime \prime}$ are registered trademarks of The American Society for Cell Biology. 
Kajfez and Matusovich, 2017). Teaching and research represent the primary roles most graduate students must balance, with these two tasks often taking the bulk of graduate student time (Austin, 2002). A GTA is hired by the institution to complete a range of tasks related to undergraduate teaching (Connolly et al., 2016), and this role often financially supports graduate students while they conduct their research. Teaching and research each have a distinct set of responsibilities and external expectations. Teaching expectations for a GTA may include lecturing, grading, attending weekly training meetings, holding office hours, or being observed teaching. For research, tasks such as project design, data collection, data analysis, grant writing, conference presentations, and ultimately publication are often expected. Some of these tasks may be more aligned with a graduate student's career interest than others (Austin, 2002; Fuhrmann et al., 2011) or in some cases messaged as more valuable to the department; for example, research is often seen as more important than teaching for science graduate students at research universities (Lane et al., 2019; Reid and Gardner, 2020). Such differences in expectations between teaching and research may cause cognitive dissonance if graduate students want to pursue more teaching-focused careers but are immersed in a departmental academic culture that seems to only value or reward research efforts. Regardless of value, these teaching and research tasks compete for a GTA's time and mental energy, and depending on a GTA's self-efficacy, motivation, and perception of task value, these responsibilities can incite anxiety (M.M.C.M., K.P., A.C., and E.E.S., unpublished data). Because teaching and research are distinct graduate student roles, the sources and nature of the student anxiety for each differ; thus we predict that the coping strategies GTAs use will also differ for each role.

In this study, we took a first step in characterizing coping strategies to manage anxiety generated from teaching and research roles within a subset of biology GTAs at one institution. The research team was primarily based in an ecology and evolutionary biology department at this institution. The research team's understanding of the teaching and research context in biology informed their decision to focus on GTAs in this discipline for this study. Although the findings from these GTAs will not be generalizable to all graduate students, their experiences can inform future studies about coping within the broader graduate student community.

\section{Coping with Anxiety Can Involve Adaptive or Maladaptive Strategies}

Coping is essential for positive individual mental health and well-being. Coping skills are a major mediating factor between stressful, anxiety-inducing events and adaptational outcomes, such as physical and psychological health, well-being, and functioning (Folkman et al., 1986). Recall that coping is an individual's behavioral and/or cognitive response(s) to external stressors, often in an attempt to reduce or tolerate the stress (Lazarus and Folkman, 1984; Folkman et al., 1986; Lazarus, 1993; Carver et al., 1989; Skinner et al., 2003; Shin et al., 2014). There are many ways that individuals cope with stressors, and attempts to categorize these strategies into similarities and differences have been an ongoing debate in the community (Skinner et al., 2003). In an extensive review on coping strategies, Skinner et al. (2003) identified several "top-down" or overarching coping categories, such as problem-focused versus emo- tion-focused coping, approach versus avoidance coping, and adaptive versus maladaptive coping (Lazarus and Folkman, 1984; Roth and Cohen, 1986; Horowitz et al., 1994). Skinner et al. (2003) proposed that, to understand coping, we need to combine existing broader categories of coping with a more inductive, context-specific approach. To this end, they developed 12 coping families that characterize existing coping strategies based on "the key role actions can play in bridging the conceptual space between coping instances and adaptive processes" (Skinner et al., 2003, p. 232). These 12 families are designed to encompass a wide variety of coping strategies seen in different individuals and contexts and were expanded by Henry et al. (2019) to 14 families (Table 1). We use the 14 families, as well as their organization into adaptive or maladaptive approaches, in this study.

Adaptive coping helps individuals successfully progress through problems and supports their well-being (Skinner et al., 2003; Henry et al., 2019). Approach-oriented, problem-focused adaptive coping can lead to positive increases in self-efficacy and effective management of anxiety (e.g., looking up information, seeking advice from a mentor). For example, if an individual coped with anxiety related to giving a lecture by preparing notes and practicing, this would be an example of the problem-solving family of adaptive coping. Conversely, the use of maladaptive coping prevents problems from being solved and can threaten an individual's well-being (Skinner et al., 2003; Henry et al., 2019). Avoiding writing tasks, social isolation, and ruminating on negative outcomes are some examples of this type of coping. For example, if an individual were to cope with anxiety about giving a lecture by avoiding thinking about it or focusing on how the lecture might go awry, then that coping approach would fall into the categories of escape and rumination. This category of coping may be considered an avoidant, emotion-focused, maladaptive response, meaning it does not effectively reduce or manage anxiety.

Henry et al. (2019) and Skinner et al. (2003) also identified "in-between" coping strategies, which may be considered adaptive or maladaptive based on the context in which the coping strategy is used and implemented. For instance, distraction is a type of avoidance coping; however, it may be used effectively to take breaks from a work task, assuming the individual returns to engage in the task. Short periods of avoidance coping can be physiologically beneficial to an individual, especially for uncontrollable situations, so long as the coping eventually shifts to strategies that are approach oriented (Lazarus and Folkman, 1984; Bandura, 1988). It is important to note that the effectiveness of a coping strategy is based on successful anxiety management, regardless of what is labeled as "good" or "bad" coping strategies, and what works for one person may not work for someone else.

Previous studies examining coping in graduate students found they used both adaptive and maladaptive coping approaches (Kjerulff and Wiggins, 1976; Nelson et al., 2001; El-Ghoroury et al., 2012; Chang and Edwards, 2015). For example, when Nelson et al. (2001) modeled stress, coping, academic success, and relative health in 53 clinical psychology students, they found adaptive coping strategies were helpful moderators of stress. Graduate students with higher grade point averages (GPAs) were more likely to use coping styles characterized by less denial, more religious coping, more 
TABLE 1. Codebook theme definitions with example actions based on coping strategies outlined from Skinner et al. (2003) and Henry et al. (2019)

\begin{tabular}{lccc}
\hline & Type of coping & Adapted definitions from & Definitions from \\
Coping themes & strategy & Skinner et al. (2003) & Henry et al. (2019) \\
\hline
\end{tabular}

1. Problem solving Adaptive coping

2. Support seeking Adaptive coping

3. Information
seeking

4. Self-reliance or Adaptive coping regulation

5. Cognitive restructuring

Adaptive coping

6. Accommodation

Either adaptive or maladaptive coping

\section{Negotiation}

Either adaptive or maladaptive coping

8. Escape

Maladaptive coping

9. Distraction
Individuals engage in instrumental action, strategizing, and problem solving.

Example action codes: planning, logical analysis, effort, persistence, determination to solve the stressor, watch and learn, mastery

Individuals seek a wide array of targets for support (e.g., parents, spouses, peers, professionals, and God) and a variety of goals in going to people (e.g., instrumental help, advice, emotional support, comfort, and contact).

Example action codes: proximity-seeking, yearning.

Individuals attempt to learn more about a stressful situation or condition, including its course, causes, consequences, and meanings, as well as strategies for intervention and remediation.

Example action codes: reading, observing, preparing, asking others for help, using external sources to resolve the stressor

Individuals attempt to influence emotional distress and to constructively express emotions at the appropriate time and place.

Example action codes: self-encouragement and self-comforting, emotional control, relaxation, emotional expression, self-soothing, internal talking to control your emotions, pep-talking

Individuals actively attempt to change their view of a stressful situation in order to see it in a more positive light; explicit positive recognition of a stressor.

Example action codes: focus on the positive, positive thinking, optimism, and minimization of distress or negative consequences

Individuals actively attempt to adjust to constraints, minimize the stress; seems to be focused on the self.

Example action codes: acceptance, also can focus on the positive or distract, and attention on redeployment

Individuals actively attempt to work out a compromise between the priorities of the individual and the constraints of the situation.

Example action codes: priority setting, proposing a compromise, persuasion, reducing demands, trade-offs, and deal making

Individuals make efforts to disengage or stay away from the stressful situation or transaction.

Example action codes: cognitive avoidance, avoidant actions, denial, and wishful thinking

Individuals actively attempt to deal with a stressful situation by engaging in an alternative pleasurable activity.

Example action codes: engage in hobbies, exercise, watching TV, seeing friends, or reading
Attempting to solve the stressor at hand, such as planning a potential solution and enacting that solution.

Use of available social resources for help with the stressor or to receive emotional comfort.

Attempting to learn more about a stressful situation or condition in order to understand the cause, consequences, or potential solutions to a problem.

Attempting to influence one's own emotional distress (to alleviate or mollify emotional distress) and to constructively express emotions at the appropriate time and place.

Attempting to change one's view of a stressor in order to see it in a more positive light.

Accepting the stressor and no longer trying to directly act to solve the stressor. Does not preclude acting to circumvent or navigate the stressor.

Proposing a compromise or making a deal with others to alleviate or solve the stressor. Individual bargaining with others/options to change situation, persuasion, compromise.

Avoidance of the problematic environment and/or stressor, including denial of the stressor.

Engaging in an alternative pleasurable activity in an attempt to alleviate emotional distress associated with a stressor. 
TABLE 1. Continued

\begin{tabular}{|c|c|c|c|}
\hline Coping themes & $\begin{array}{c}\text { Type of coping } \\
\text { strategy }\end{array}$ & $\begin{array}{l}\text { Adapted definitions from } \\
\text { Skinner et al. (2003) }\end{array}$ & $\begin{array}{l}\text { Definitions from } \\
\text { Henry et al. (2019) }\end{array}$ \\
\hline 10. Isolation & Maladaptive coping & $\begin{array}{l}\text { Individuals withdraw from interaction, hide, avoid } \\
\text { others to hide the anxiety; particularly with } \\
\text { individuals they have social capital with } \\
\text { (friends, family, etc.). Actions are aimed at } \\
\text { staying away from other people or preventing } \\
\text { other people from knowing about a stressful } \\
\text { situation or its emotional effects. } \\
\text { Example action codes: social isolation, avoiding } \\
\text { others, concealment, stoicism, and emotional } \\
\text { withdrawal }\end{array}$ & $\begin{array}{l}\text { Avoiding other people to hide stressors or } \\
\text { preventing other people from knowing } \\
\text { about a stressor or its effects. }\end{array}$ \\
\hline 11. Rumination & Maladaptive coping & $\begin{array}{l}\text { Individuals concentrate on the negative features } \\
\text { of a situation. Passive and repetitive focus on } \\
\text { the negative and damaging features of a } \\
\text { stressful transaction. } \\
\text { Example action codes: intrusive thoughts, } \\
\text { negative thinking, catastrophizing, anxiety } \\
\text { amplification, self-blame, fear, and submission }\end{array}$ & $\begin{array}{l}\text { Repeatedly thinking negatively about a } \\
\text { stressor and about one's own role in } \\
\text { that transaction. Associated with } \\
\text { catastrophizing and self-blame. }\end{array}$ \\
\hline 13. Delegation & Maladaptive coping & $\begin{array}{l}\text { Individuals blame another person or situation for } \\
\text { their anxiety; a negative social interaction. } \\
\text { Example action codes: complains, whines, } \\
\text { expresses self-pity, dependency, or maladaptive } \\
\text { help-seeking }\end{array}$ & $\begin{array}{l}\text { Shifting the problem to someone else } \\
\text { through maladaptive help seeking such } \\
\text { as whining and self-pity. }\end{array}$ \\
\hline 14. Opposition & Maladaptive coping & $\begin{array}{l}\text { The individual expresses aggression, anger, } \\
\text { blaming, defiance with a situation or issue. } \\
\text { Example action codes: projection, reactance, } \\
\text { anger, aggression, discharge, venting and } \\
\text { blaming of others }\end{array}$ & $\begin{array}{l}\text { Externalizing one's negative emotions as } \\
\text { behaviors directed at others in } \\
\text { connection with the stressor. }\end{array}$ \\
\hline
\end{tabular}

venting and expressing emotions, and greater seeking of instrumental emotional social support (Nelson et al., 2001). Students also reported some in-between or maladaptive strategies such as mental disengagement, suppression of competing activities, humor, alcohol and drugs, denial, or behavioral disengagement (Nelson et al., 2001).

Research has shown how graduate students cope with stressors in their programs broadly; however, no work has been done to identify the specific coping strategies that GTAs employ to manage anxieties that arise from their teaching and research roles, including whether they are employing adaptive, maladaptive, or in-between strategies or combinations of these strategies for each role. Because previous research has identified a preponderance of adaptive coping strategies in graduate students, we expect to find that those strategies will be most frequent in coping with teaching and research; however, because teaching is considered of lower value than research and may be perceived as less important, we predict that there may be more maladaptive, avoidant strategies associated with teaching compared with research.

\section{Coping Strategies Can Change over Time}

Coping for teaching and research roles may change over time for graduate students, because research indicates coping strategies in general can shift over time (Gintner et al., 1989; Lazarus, 1993; Spencer et al., 1997; Ickes et al., 2015). As students enter graduate school and adjust to their new roles, they may need to employ new coping strategies, because the nature of the stressors is different from past experiences or their perceptions of the anticipated research or teaching event has changed, thus changing the experience of anxiety over time. As anxiety changes, subsequent changes in coping strategies may be expected.

How coping changes over time can vary. Stressful life events, for example, challenge how individuals cope, leading to the need for more diverse strategies (Edward and Warelow, 2005). However, coping theories suggest that, over time, certain coping 
approaches may become a stable characteristic of an individual or context. Spencer et al. (1997) showed that an individual's coping responses to similar situations became increasingly consistent over time. We posit that, as graduate students are challenged with new teaching and research roles, they are likely to experience some fluctuation in coping strategies as they test new methods to cope with these new stressors. However, as they adjust to the new roles and their associated anxieties, GTAs should settle on certain strategies that are effective in these new contexts. To begin to explore these predictions, we assessed GTA coping strategies twice over one year to see whether participant strategies were stable over that time period.

\section{Rationale for Our Study}

For many graduate students, being a teacher and researcher represents distinct yet important roles they must balance. When the value of research and teaching within an institution is messaged to graduate students as a hierarchy (Colbeck, 2008; Reid and Gardner, 2020), students can have different perspectives and feelings toward them (M.M.C.M., K.P., A.C., and E.E.S., unpublished data). Because teaching and research are distinct roles (Austin and Wulff, 2004; Reid and Gardner, 2020), we predict that these differences will carry through to the emotions students feel about each role, including feelings of anxiety and coping strategies. We further predict that the way in which GTAs cope with teaching and research anxiety may differ over time.

Effective coping in these roles is important because of its positive outcomes. For example, effective coping contributes to increased self-efficacy (Crego et al., 2016), greater job satisfaction (Chang and Edwards, 2015), and improved mental health outcomes (Mackie and Bates, 2019). For graduate students, it may also positively reinforce an individual's career pursuits (Lent et al., 1994). When surveying biomedical doctoral students, Fuhrmann et al. (2011) found that one of the reasons students decided not to pursue faculty positions was due to the stress associated with succeeding in academia; effective alleviation of this stress may help maintain graduate student academic career intentions. Effective coping by graduate students also benefits academia more broadly by supporting their important functions as instructors of undergraduate students (Sundberg et al., 2005) and producers of intellectual knowledge through their research (National Academies of Sciences, Engineering, and Medicine [NASEM], 2018). Therefore, this study can help inform what faculty mentors and departments can do to help foster effective coping among graduate students.

To better support graduate students' mental health, career aspirations, and important roles within academia, we need to understand what coping strategies they are employing to manage anxieties that arise during their graduate programs. This study investigated how 23 biology GTAs at one large research-intensive southern U.S. university coped with teaching and research anxieties at two time points over one year (Fall 2016 and Fall 2017). To our knowledge, this is the first qualitative study to examine biology GTA coping to teaching and research anxieties. Our research questions were twofold:

1. What coping strategies do biology GTAs employ to manage teaching and research anxieties?

2. How do biology GTA coping strategies change over one year?

\section{METHODS}

\section{Study Population}

Our study population was drawn from biology GTAs at a large research-intensive southern university (IRB-16-03235-XP). The GTAs were recruited via email from across three biology departments and one program in the Division of Biology. As of Fall 2016, 211 graduate students in these units were enrolled in a master's or $\mathrm{PhD}$ program, with $94 \%$ of graduate students seeking $\mathrm{PhDs}$, 55\% identifying as female, and the majority being white.

\section{Data Collection}

In October 2016, an online survey was deployed to biology graduate students via the Qualtrics survey software. An email was sent to recruit individuals who were either currently teaching or who had been GTAs to take the survey. This survey collected quantitative data for another study on teaching and research anxieties (M.M.C.M. and E.E.S., unpublished data), but was also used to recruit participants for this qualitative study. At the end of the survey, participants were asked if they were "interested in volunteering to participate in a brief follow-up interview?" If they indicated "yes," they were then prompted to enter their names and email addresses. Of the 89 biology GTAs who completed the survey, 26\% $(n=23)$ indicated that they would be interested in participating in follow-up interviews.

Interviews of graduate students were conducted twice over one year to collect in-depth perceptions of how GTAs coped with teaching and research anxiety and whether their strategies changed over the year. From the Fall 2016 survey, we collected participants' gender, ethnicity, citizenship status (international vs. domestic), teaching experience (number of semesters as a GTA), age, degree program, year in the graduate program, and departmental affiliation. GTAs in the interview pool were $70 \%$ female and 74\% white (see Table 2 and Supplemental Table 1 for demographics). All interviews were conducted by the first author (M.M.C.M.). Each interview ranged between 60 and 90 minutes in length. Participants were given a small monetary compensation of $\$ 10$ per interview, which was disseminated onto their student cards after the interview was complete.

\section{Biology GTA Interviews}

Interviews were conducted with the same 23 graduate students in Fall 2016 and again in Fall 2017 using the same interview protocol (see Supplemental Material), with a few retrospective questions added in 2017. Interview questions probed four main topics: 1) GTAs' perceptions of their experience levels in teaching, knowledge of teaching, and effectiveness in teaching; 2) their teaching and research anxieties; 3) coping strategies enacted for each anxiety; and 4) their professional identities/ career aspirations as teachers and researchers. To answer our research questions for this study, we focused on analyzing the participant reports of coping strategies from these interviews. The data on anxieties related to teaching and research were previously analyzed as a separate study due to the length of the qualitative results (M.M.C.M., K.P., A.C., and E.E.S., unpublished data).

Card sorts were used as an interview tool to guide conversations and ease the participants into discussions about sensitive topics. Card sorting is a method employed to examine 
cognitive structures and processes (Spradley, 1979; Weller and Romney, 1988), and encourage the individual to express internal cognitions and schemas (Blake et al., 2007). Card-sort activities can be used as interactive, object-based aids in qualitative interviews to help participants make abstract concepts more tangible (Conrad and Tucker, 2019). For these interviews, card sorts were used to help participants more easily categorize and conceptualize their teaching anxiety, research anxiety, and coping (see Supplemental Material). To do this, we prepared two sets of cards, one set of cards contained hypothesized factors or situations that may relate to teaching anxieties (student behavior, grading, etc.) and the other set contained hypothesized factors related to research anxieties (publishing, data analysis, etc.). Blank cards were also available for participants to write their own factors not captured by the existing cards.

The interview protocol and card-sort items were vetted by two faculty members, one biology education postdoctoral researcher, and two biology graduate students, all trained in both biology and biology education research (including authors M.M.C.M. and E.E.S.). The collective knowledge of these individuals as current and former graduate students, researchers who study anxiety, introductory biology instructors, and an advisor to graduate students was used to inform the questions and list of factors that may be associated with GTA anxiety. Together, we reflected on our own graduate school experiences and identified the factors that caused us anxiety and then further considered the factors causing anxieties in the graduate students in our department, as related to teaching and research.

Before reading the cards, participants were first asked to list on a sheet of paper any teaching and research anxieties they experienced. This prevented the predetermined card topics from unduly influencing participant responses during the interview. If the given card-sort topics failed to capture a participant's teaching or research anxieties, it would be captured in this initial anxiety listing and added as a new card. Participants then read the prepared sets of cards, picked relevant anxiety cards for teaching and research, respectively, and ranked them from greatest to least anxiety. They then explained what about the factor on the card made them anxious and described how/if they coped with that factor. Participant descriptions of how they coped with their identified anxieties were the focus of this study. We note here that all 23 participants chose cards and discussed anxieties related to teaching and research; however, they did not always have an identified coping strategy for each anxiety. Interviews from 2016 and 2017 were audio-recorded and transcribed to conduct qualitative content analysis.

Pseudonyms, aligned with the participant's self-reported gender and ethnicity, have been used throughout the results. Although some have advocated for the use of gender-neutral pseudonyms, previous research has shown some differences between genders in coping strategies (e.g., Matud, 2004), and we felt that maintaining this information would be important for those who are interested in potential differences based on contextual and demographic characteristics of individuals. Anglicizing a person's identifiably ethnic name was also avoided to maintain accurate representation of our GTAs' self-reported identities.
TABLE 2. Demographics of the 23 biology GTAs interviewed in 2016 and 2017

\begin{tabular}{|c|c|c|}
\hline & $N$ & $\begin{array}{c}\text { Percentage of total } \\
\text { participants }(n=23)\end{array}$ \\
\hline \multicolumn{3}{|l|}{ Gender } \\
\hline Male GTAs & 7 & 30 \\
\hline Female GTAs & 16 & 70 \\
\hline \multicolumn{3}{|l|}{ Citizenship status } \\
\hline Domestic & 17 & 74 \\
\hline International & 6 & 26 \\
\hline \multicolumn{3}{|l|}{ Ethnicity } \\
\hline White & 18 & 78 \\
\hline Non-white & 5 & 22 \\
\hline \multicolumn{3}{|l|}{ Experience level $^{\mathrm{a}}$} \\
\hline Novice & 10 & 43 \\
\hline Experienced & 13 & 57 \\
\hline \multicolumn{3}{|l|}{ Degree } \\
\hline MS & 4 & 17 \\
\hline $\mathrm{PhD}$ & 19 & 83 \\
\hline \multicolumn{3}{|l|}{ Year in program } \\
\hline 1 & 9 & 40 \\
\hline 2 & 7 & 30 \\
\hline 3 & 7 & 30 \\
\hline \multicolumn{3}{|l|}{ Department ${ }^{\mathrm{b}}$} \\
\hline BCMB & 2 & 9 \\
\hline EEB & 12 & 52 \\
\hline GST & 3 & 13 \\
\hline Micro & 5 & 22 \\
\hline Other & 1 & 4 \\
\hline
\end{tabular}

aExperienced GTA: > 1 year of GTA experience; novice GTA: $<1$ year of GTA experience.

${ }^{\circ}$ BCMB, Biochemistry \& Cellular and Molecular Biology; EEB, Ecology and Evolutionary Biology; GST, Genome Science and Technology; Micro, Microbiology.

\section{Data Analysis}

Using the 14 coping families of Skinner et al. (2003) and Henry et al. (2019) as a working codebook, we conducted a priori content coding on the portion of the interview data related to participant responses on coping (Charmaz, 2006; Strauss and Corbin, 2008; Saldaña, 2012). The data corpora for coping to teaching and coping to research were analyzed separately for each participant, with each data set being read and segments of the data assigned a code reflecting one of the Skinner categories. Thus, the coping data represent the composite coping strategies used for teaching and then research for each participant.

In a priori coding, researchers use an existing codebook and identify and categorize participant ideas within given themes (Saldaña, 2012). Even with an established coding scheme, qualitative content analysis still requires careful, iterative reading of the text (White and Marsh, 2006; Flick, 2014). The codebook for this study contained five adaptive coping strategies, six maladaptive coping strategies, three in-between coping strategies that could be either adaptive or maladaptive depending on the context, and one category for no coping strategy (Tables 2 and 3). Each coping strategy was treated as its own theme.

The initial codebook (Table 2) was created by first author (M.M.C.M), by using coping definitions from Henry et al. (2019) and adapting definitions offered by Skinner et al. (2003). 
TABLE 3. Illustrative quotes for each coping strategy from biology GTAs

\begin{tabular}{|c|c|c|}
\hline Coping themes & $\begin{array}{c}\text { Type of coping } \\
\text { strategy }\end{array}$ & Illustrative quote(s) in teaching \\
\hline 1. Problem solving & Adaptive coping & $\begin{array}{l}\text { "I try to plan and carve out time to prep for } \\
\text { teaching. If I know it's going to take me } 3 \\
\text { hours to prep my lesson, I carve out a block } \\
\text { of } 3 \text { hours where I can work on that." } \\
\text { - -Hannah, } 2017\end{array}$ \\
\hline 2. Support seeking & Adaptive coping & $\begin{array}{l}\text { "But if I feel very unhappy I definitely will talk } \\
\text { with someone and see how to deal with it." } \\
\text {-Sunny, } 2016\end{array}$ \\
\hline $\begin{array}{l}\text { 3. Information } \\
\text { seeking }\end{array}$ & Adaptive coping & $\begin{array}{l}\text { "I try to bring my student's questions with me to } \\
\text { my TA meetings so I can get answers from } \\
\text { people who know better and report back to } \\
\text { them."-Jack, } 2017\end{array}$ \\
\hline $\begin{array}{l}\text { 4. Self-reliance or } \\
\text { emotional } \\
\text { regulation }\end{array}$ & Adaptive coping & $\begin{array}{l}\text { "Sometimes I get really frustrated on the inside } \\
\text { so I try to take some deep breaths." } \\
\text { - Lauren, } 2017\end{array}$ \\
\hline $\begin{array}{l}\text { 5. Cognitive } \\
\text { Restructuring }\end{array}$ & Adaptive coping & $\begin{array}{l}\text { "The way to cope is...I'm just going to read it } \\
\text { [student evaluations] and I'm going to take } \\
\text { it as good criticism or criticism to } \\
\text { improve."-Raegan, } 2016\end{array}$ \\
\hline 6. Accommodation & $\begin{array}{l}\text { Either adaptive or } \\
\text { maladaptive } \\
\text { coping }\end{array}$ & $\begin{array}{l}\text { "Shut up and grade? Like you just do it and } \\
\text { have no choice. It has to get done and the } \\
\text { students need it." - Madison, } 2017\end{array}$ \\
\hline 7. Negotiation & $\begin{array}{l}\text { Either adaptive or } \\
\text { maladaptive } \\
\text { coping }\end{array}$ & $\mathrm{N} / \mathrm{A}$ \\
\hline
\end{tabular}

$\begin{array}{ll}\text { 8. Escape } & \text { Maladaptive copin } \\ \text { 9. Distraction } & \begin{array}{l}\text { Either adaptive or } \\ \text { maladaptive } \\ \text { coping }\end{array}\end{array}$

10. Isolation

11. Rumination

12. Helplessness

13. Delegation

14. Opposition

15. No Coping
Maladaptive coping

Maladaptive coping

Maladaptive coping

Maladaptive coping

Maladaptive coping

N/A
"I do my absolute best to just block it out when I'm teaching, which I can do."-William, 2017

"I'd say I actually look at teaching or prepping to teach as kind of an escape from the anxiety of research, so the time away from my research while I'm in that time away from it I actually enjoy it."

—William, 2017

\section{N/A}

"Yeah and it stays with you forever. Just stays in your head and you can't get over it."-Hannah, 2017

"I don't know if I really do anything for it. I mean I don't think I change my behavior."Mark, 2016

N/A

"Sometimes I just tell my students to shut up and it makes me feel like I have authority." —Jack, 2017

"I don't really [cope]. I don't know." —Laretta, 2017

\section{Illustrative quote(s) in research}

"I read over experiments several times, then I try to ask questions and figure out how to conduct that lab work and see how much time it's going to take to be able to do it." -Hannah, 2017

"I've talked to my peers about it. Other women in the sciences, and they say they struggled [with] the same exact same stressor."-Emily, 2016

"I dig through the literature and try to make inferences on what I think is important." -Samantha, 2016

"I just try to tell myself 'It's okay, you don't have to know everything."'-Raegan, 2016

"If critique impacts me in a positive way then I see benefit from it and then I work on it." -Hannah, 2016

"I think that the best way for me to cope with it is to find that peak productivity time and just go with it."-Hannah, 2016

"I think it may take, because, like, the topic I'm doing now I first brought up the beginning of this year he's not interested. Then, I brought up again this summer, still not interested, but I still keep doing. Then, he was kind of convinced. 'Okay, you can do this."'-Sunny, 2017

“When I really don't want to deal with it, I ignore it. Just let it sit in my inbox and slowly get pushed under these new things and get reminded later."-Laretta, 2017

"I impulse buy online to cope with my stress." -Laretta, 2017

N/A

"I feel like I do the opposite of coping with it because I think about it too much."-Sarah, 2017

"I'll worry but it's not going to change anything."-Raegan, 2016

N/A

N/A

"I don't know if I do cope with it."-Lucy, 2017 
A coding unit was defined as the GTA response to how they coped with one factor that caused anxiety for them in relation to either teaching or research (one card response). The first author and three undergraduate research assistants (coauthors A.C., O.F., and K.P.) used the codebook to iteratively analyze the biology GTA interview transcripts from 2016 and 2017 (Glaser and Strauss, 1967; Schwandt, 2007). In each round of analysis, researchers independently coded six randomly selected interview transcripts. Researchers could assign as many codes as existed for each participant response, thereby possibly having multiple codes per coding unit. These codes were then compiled for each participant.

We used a modified interrater reliability (IRR) for this study because Cohen's kappa and other interrater statistics are calculated upon the assumption that there is only one code per coding unit (Burla et al., 2008). Because we had four coders and they could assign more than one code per coding unit, only when all coders found the same sets of codes per unit, which may be upward of two to three codes, was "agreement" counted. We calculated IRR as a percentage of agreement among four raters (LeBreton and Senter, 2008) by:

1. summing how many times Coders $1,2,3$, and 4 agreed on all codes per coding unit; and

2. then determining the percentage of agreement between coders among each interview.

For example, if there were four coding units to be coded, and Coders 1, 3, and 4 agreed on all the codes, but Coder 2 disagreed on one of them, then the IRR percent calculation would be as follows: $4 / 4+4 / 4+4 / 4+3 / 4=93.75 \%$ agreement, because four of four coders agreed on all codes in the first three interview units, while only three coders agreed on the last interview unit. We calculated IRR between coders among the six randomly selected interview transcripts. If the coding agreement was lower than $80 \%$, coders would re-examine their understanding of the codebook definitions and recode a new set of randomly selected transcripts. Three iterations of this method were conducted until we reached a minimum IRR of $80 \%$ for all the randomly selected interviews (Landis and Koch, 1977). Two coders (O.F. and K.P.) then coded the remaining Fall 2016 and 2017 interview transcripts, checking in with each other and the other two coders (M.M.C.M. and A.C.) about any discrepancies or confusion. Any further disagreements were reconciled among the four coders.

\section{RQ1: What Coping Strategies Do Biology GTAs Employ to Manage Teaching and Research Anxieties?}

To answer the first research question, we took two approaches to analyzing and presenting the data: 1) compiling the coping strategies data for all participants to view overall patterns, and 2) presenting the coping strategies data for each participant to see the diversity of ways that each individual coped. We only used the 2016 interview data set for these analyses; the 2017 data set was used to answer the second research question (discussed later).

To compile the data, we tallied the presence and absence of each coping strategy for each participant for teaching and research anxieties, respectively. For example, if a participant indicated he or she coped with anxiety about grading consistently by making a rubric, we would designate that participant as having coped through problem solving. Coping was not tallied by fre- quency of use by an individual; if the participant mentioned a strategy that was coded as problem solving multiple times, it was still only counted once for that individual. After tallying the emergence of each theme among individual GTA participants, we calculated a total percent emergence for each coping strategy related to teaching and research in the sample of all GTA participants. For instance, if 20 participants in 2016 indicated they coped with teaching anxiety through problem solving, the percent emergence of that theme in the population in 2016 would be $(20 / 23) \times 100=87 \%$. These tallies were displayed as a figure depicting the total percentage of participants who used each coping strategy for teaching and then research anxiety.

To represent coping strategies of each participant, we compiled a table showing how each participant coped with teaching and research anxieties. To focus our discussion of the results, we used the compiled results of the entire data set to identify the most common coping strategies used by participants overall for teaching and/or research. This led us to focus only on participants' use of problem solving, support seeking, information seeking, self-reliance, cognitive restructuring, accommodation, and distraction. All coping strategy results are shown in Supplemental Tables 2-7. For all participant results, the coping strategy was indicated as present or absent in terms of the participant discussing that strategy during the interview.

\section{RQ2: How Do Biology GTA Coping Strategies Change Over One Year?}

To answer our second research question about how coping strategies may change over time, we compared percent emergence of the same coping strategies for teaching and research in the compiled participant group in 2016 versus 2017. We once again took a two-pronged approach wherein we compiled the data in regard to changes in coping strategies for all participants and then selected coping strategies to highlight for an individual analysis of how each participant changed or did not change coping strategies over one year.

To compile the ways in which coping strategies changed over a year, we looked at individual participant results from 2016 and 2017 and tallied for each coping strategy whether it was kept (coping strategy used both years), abandoned (coping strategy used in 2016, but not 2017), added (coping strategy used in 2017, but not 2016), or never used (coping strategy used in neither year) between the two time points. We then compiled these results for teaching and research coping strategies for all 23 participants. Due to time constraints during their interviews, three participants (Mark, Lauren, and Raegan) were not asked about how they coped with their research anxieties in 2017, and thus have been removed from these over time analyses $(N=20$ for research coping in 2017). We further compiled the coping strategies into adaptive, in-between, and maladaptive coping strategies for presentation. To depict the change in the use of each coping strategy specifically, we calculated the difference between the total percent of GTAs using a coping strategy from 2016 and 2017. We also split the data set into novice and experienced GTAs to ascertain whether new GTAs were more likely to shift strategies compared with GTAs with more teaching or research experience. GTAs are designated "novice" if they have $<1$ year of teaching experience and "experienced" if they have $>1$ year of teaching experience. These designations also often coincided with graduate students being early and late in their 
graduate programs, respectively. Finally, to explore how each participant changed coping strategies over time, we produced tables showing the presence or absence of all coping strategies in the 2016 and 2017 interviews (Supplemental Materials).

\section{Methodological Limitations}

The data are constrained to the sample we obtained, and we had more women volunteer to be interview participants compared with men $(70 \%$ and $30 \%$ of our sample population, respectively). The literature suggests that women graduate students have increased risk of developing a psychological stressor compared with men (Evans et al., 2018) and are more likely to report this stressor (Barsky et al., 2001). Men may report or discuss their mental health less frequently, because of a perception that it is a stigmatized topic or has the potential to jeopardize their perceptions of themselves (Organisation for Economic Co-operation and Development [OECD], 2014). Therefore, the coping strategies that have emerged in our study may apply more specifically to women GTAs.

Calculating IRR using percent agreement has both its advantages and disadvantages. Percent agreement has often been calculated between two coders and is an easy, intuitive measure of qualitative reliability (Krippendorff, 2004; Stemler, 2004). However, it has also been criticized for the potential to artificially inflate percent agreement if there is a generally low incidence of theme occurrence (Hayes and Hatch, 1999; Stemler, 2004). Our calculation of IRR as percent agreement, however, is not simply between two coders, nor does it assume one code per coding unit. Agreement was counted only when all coders found the same sets of codes per unit. This made our calculation of IRR more conservative than typical percent agreement calculations.

\section{RESULTS}

We present our results in two sections, one for each research question (What coping strategies do biology GTAs employ to manage teaching and research anxieties? How do biology GTA coping strategies change over one year?). For each section, we first present the compiled results across all participants and then the results by participant. We then profile participant interview quotes to highlight the specific ways in which the coping strategies were enacted in response to teaching and research anxiety. Whenever possible, we present a participant's quotes verbatim; however, some quotes have been lightly edited for clarity. If changes were made to the original quotes, we indicated this with square brackets.

We predicted that GTAs would cope with their distinct professional roles in teaching and research differently, that adaptive coping strategies would be used more often, and that coping strategies would change over time. Overall, our results supported our predictions: 1) there was a difference in coping strategies that GTAs used to ameliorate research anxiety versus teaching anxiety; 2) adaptive coping strategies were used more than maladaptive strategies by GTAs; and 3) GTA use of several coping strategies appeared to decrease over time.

\section{GTAs Mentioned a More Diverse Set of Coping Strategies to Manage Research Anxieties Compared with Teaching Anxieties}

Generally, the coping strategies of problem solving and information seeking were discussed most frequently by GTA partici-

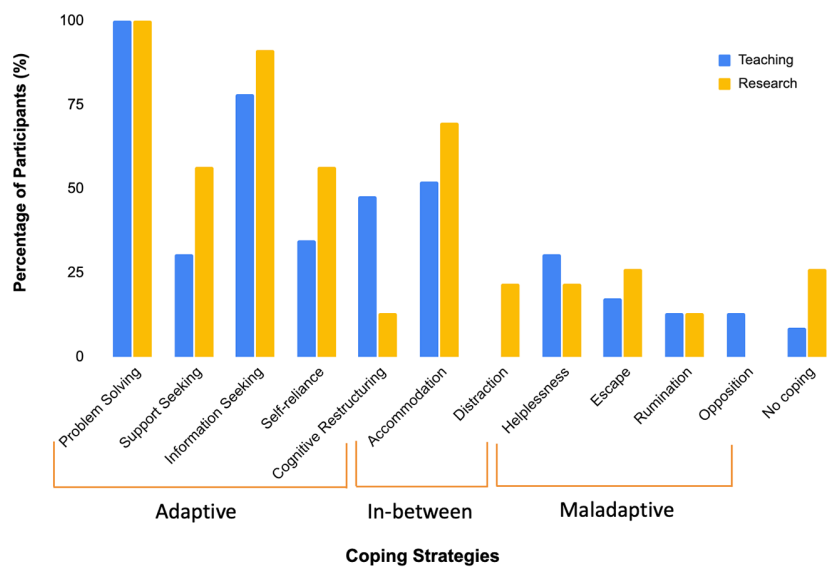

FIGURE 1. Coping strategies that emerged among 23 biology GTA participants in response to teaching and research anxieties in 2016. The $y$-axis shows the percent emergence of the strategy in terms of usage by individual GTAs, but not frequency of usage.

pants to manage anxieties related to both teaching and research (Figure 1). However, certain coping strategies were mentioned more when discussing research roles versus teaching roles. GTAs spoke more about using support seeking, self-reliance, accommodation, and distraction when managing research anxieties compared with teaching anxieties. GTAs would also more often state they did not cope with a stressor for research as opposed to teaching. Conversely, GTAs discussed using more cognitive restructuring to deal with teaching anxieties. Most of these strategies were adaptive in nature, with in-between and maladaptive strategies being discussed much less often by participants.

Examining the range of coping strategies used individually, we found that GTA participants used a more diverse set of coping strategies to ameliorate research anxieties compared with teaching anxieties, with GTAs using between two and six coping strategies to manage teaching anxieties and between three and eight for research anxieties (Supplemental Table 8). Individual participants did not always use the same combination of coping strategies to manage anxieties for teaching and research (Supplemental Table 8). The strategies of support seeking, self-reliance, and cognitive restructuring were often used for teaching or research, but not both. Ten GTA participants used only adaptive coping strategies when ameliorating teaching anxiety, whereas only two GTAs had only adaptive coping strategies for research. For example, for research anxieties, Anika only used problem solving, support seeking, information seeking, and self-reliance. For managing research anxieties, there was often a mix of adaptive and maladaptive coping strategies (three GTAs), adaptive and in-between strategies (10 GTAs), or all three (eight GTAs). In total, for teaching anxieties, 10 different coping strategies were used (five adaptive, one in-between, four maladaptive); and for research, 10 different coping strategies were also used (five adaptive, two in-between, three maladaptive).

Examining the compiled and individual results for how GTAs coped with teaching and research anxieties, we found that the most commonly employed coping strategies were either adaptive (problem solving, support seeking, information seeking, 
self-reliance, and cognitive restructuring) or in-between strategies (accommodation and distraction). Helplessness was the most common maladaptive coping strategy employed by GTAs, though this strategy was overall rarely mentioned by GTAs. In the following sections, we highlight how participants used each of those coping strategies to try to ameliorate their teaching and research anxieties.

\section{Problem Solving (Adaptive)}

For both teaching and research contexts, the adaptive coping strategy of problem solving emerged often and consistently to resolve anxieties (Figure 1), with all 23 GTAs using this strategy. Coping by problem solving was often characterized by GTAs talking about practicing, planning, or preparing in advance for given tasks or situations that incited anxiety. For example, Sarah, a first-year GTA, spoke about how she coped with anxiety related to presenting her research during a departmental seminar: "When I gave my talk, I made the time to practice a lot and read a couple of key papers." Similarly, experienced GTAs like Hannah tackled anxieties related to research by formulating a plan to ensure she had the greatest control or efficacy over the issue. When she described anxiety in carrying out her lab work, particularly for fear of "messing it up," Hannah employed problem solving: "I read over experiments several times, then I try to ask questions and figure out how to conduct that lab work and see how much time it's going to take to be able to do it."

In managing teaching anxieties, problem solving also emerged as a top coping strategy among biology GTAs, again with all 23 GTA participants using this strategy. This coping strategy was characterized by planning around anticipated classroom or student-related issues. For example, William, an experienced GTA with career aspirations to work with a governmental organization, coped with anxiety in not knowing the teaching topic by "just really diving into the stuff" and preparing for class by "look[ing] at all the material. I'm one of the TAs that, when [they] give you the TA manual, I read the whole thing." When Julia and Mark expressed anxiety about grading fairly, they coped by developing assignment rubrics. Mark described how the teaching professional development (PD) he received guided his rubric development: "I try to make my rubrics more lenient, like not being as specific in what I'm expecting or also-I think it was in professional development[for me to] think about how they earn points, not how they lose points." During interviews, problem-solving strategies were identified when GTAs shared a plan they had used or would potentially use to resolve a self-reported anxiety.

\section{Information Seeking (Adaptive)}

Coping through information seeking was another common adaptive coping strategy employed by biology GTAs to manage anxieties, with 18 and 21 GTAs using it for teaching and research anxieties, respectively (Figure 1). As the name suggests, GTAs would attempt to learn more about an issue or anticipated anxiety in order to better understand its causes or consequences. This strategy was often paired with problem solving, as GTAs also sought more information as part of their plans to control a situation, with 17 GTAs using both problem solving and information seeking to ameliorate anxieties in teaching and research. Recall that problem solving involves planning or preparing oneself for a task that incites anxiety, while information seeking involves gathering more knowledge or ideas related to carrying out a task. Thus, to demarcate problem solving from information seeking, we looked for differences in whether the participant was collecting information or creating a plan of action. Information was acquired through other people (mentors, workshops) or from consulting another source (literature, Internet). In teaching contexts, information seeking was often employed when GTAs were anxious about aspects of their classrooms or pedagogies that were unknown or not within their control. For example, Jack, a first-year GTA, indicated that to manage his worries over not effectively supporting student learning, he asked colleagues at TA meetings the student questions he receives: "I try to bring my students' questions with me to my TA meetings so I can get answers from people who know better and report back to them." This type of information seeking is also reflected in tackling anxieties in research. When GTAs indicated anxiety in being unable to carry out statistical analysis or data collection for their research, they would talk to others or look through papers or books.

In this strategy, some GTAs would seek specific external resources to help them learn more about a particular task, such as pedagogy classes or PD workshops. For example, to cope with teaching anxiety related to not knowing the best teaching practices to use in his classrooms, Jose, an international firstyear GTA, credits his attendance at teaching PD workshops from the Center for the Integration of Research, Teaching and Learning (CIRTL). When Jose needed to manage research anxiety related to writing, he would similarly look for writing courses or workshops to provide advice on how to improve his writing: "You can take seminars about how to write better and I'm going to be taking a writing class next semester and hopefully that'll give me new techniques just like CIRTL gave me techniques [in teaching]." Some GTAs, like Rebecca or Anika, also mentioned attending workshops to manage research anxieties, such as applying for grants or fellowships or for data analysis guidance. To cope with correctly working with new software or research tools, Anika, an international, experienced GTA, said: "I know the library offers many courses like experimental techniques, so I try to go to the majority of them. Like even if it's small little things, try to go and learn how the software works."

\section{Support Seeking (Adaptive)}

Support-seeking strategies were discussed among GTAs to primarily combat research anxieties, with 13 GTAs using this strategy for research contexts, and only seven GTAs using them to ameliorate anxiety in teaching (Figure 1). This type of strategy is characterized by individuals seeking camaraderie, comfort, or emotional support from trusted confidants. When this strategy was evoked among our GTAs, they would describe reaching out to their social networks. For example, Anika spoke about how she would "talk to other graduate students who have finished [and] gone through the same process" when coping with uncertainty after graduation. Support seeking was sometimes paired with information seeking (11 GTAs used both information seeking and support seeking for research), when a GTA sought further information in managing the anxiety along with positive emotional support or advice. For example, when Hannah, an experienced GTA who hoped to find a career as a government scientist or in industry, expressed research anxiety related to 
feeling like an imposter in the program, she coped through "talking to people about feeling down or feeling like an imposter. [Talk to] those who will lift me up." In another interview, Laretta, a senior doctoral candidate, spoke about how she looked to her female colleagues for support when she struggled with a lab mate suggesting that her accolades were attributable to her gender and not the merit of her work: "I've talked to my peers about it. Other women in the sciences, and they say they struggled [with] the exact same thing." Laretta and another GTA, Kaitlyn, also spoke about seeing a therapist or being on medication to help with anxiety related to thinking about their careers after graduate school. This suggests that having a supportive social network or professionals to rely on are important GTA needs.

\section{Self-Reliance (Adaptive)}

Another adaptive coping strategy mentioned more in research (13 GTAs) than in teaching (8 GTAs) was self-reliance (Figure 1). Also known as emotional regulation, self-reliance is when individuals attempt to alleviate or modify their emotional distress and to constructively express emotions at the appropriate time and place. Biology GTAs in our sample would express self-reliance similar to a positive self-pep talk to encourage themselves in the moment. For example, to ameliorate anxiety related to giving a seminar talk, Laretta would convince herself that "just having the confidence to go in there is better than having a script memorized." This strategy was also manifested in teaching. For instance, Lauren, a first-year master's student, explained how she dealt with being unable to answer student questions right away: "After the class is over, I try to reassure myself and figure out things I can do with the next class."

\section{Cognitive Restructuring (Adaptive)}

GTAs employed cognitive restructuring more often as a coping strategy when managing teaching anxieties (11 GTAs) compared with research anxieties (three GTAs). This adaptive strategy is characterized by individuals attempting to change their perspective of a stressor to see it in a more positive light. Often, GTAs used this strategy when they turned their anxieties into an opportunity for self-growth. For example, Raegan, a first-year GTA, used cognitive restructuring to positively receive feedback from teaching evaluations and make improvements for the future: "I'm just going to read it and I'm going to take it as good criticism or criticism to improve." Similarly, when Kaitlyn was anxious about being observed teaching, she would remind herself that "getting the observation comments back was a good thing because it actually told me that I wasn't doing too terribly at all at this." This strategy was used among both new and experienced GTAs for anxiety related to evaluations (e.g., from students or instructors).

\section{Accommodation (In-Between)}

The in-between coping strategy of accommodation also arose more often among GTAs to manage research anxieties (16 GTAs) compared with teaching (12 GTAs; Figure 1). Recall that in-between coping strategies could be adaptive or maladaptive depending on the implementation and effect on individual well-being. This strategy is characterized by individuals accepting or adjusting to a stressor and no longer trying to directly act to solve it. GTAs would use accommodation by adjusting aspects of the situation or environment they could control, in order to endure the stressor. For example, when Kayla was anxious about meeting her advisor and having her research progress reviewed, she would "read the literature and drink beer" and then "meet with him and the anxiety goes away." Here, Kayla pairs an information-seeking strategy with accommodation to prepare for the meeting. In other examples, GTAs would explain how they would "just keep going" or endure the activity/task related to their anxiety as they saw no other way to manage it. To cope with anxiety in being reviewed by her advisor through progress reports, Rebecca indicated she would "just keep going I guess."

\section{Distraction (In-Between)}

Five GTAs also employed distraction, another in-between coping strategy, to cope with research anxieties, with no GTAs using this strategy in teaching (Figure 1). This coping strategy can be characterized by GTAs engaging in a different activity in an attempt to alleviate emotional distress associated with the main stressor. If distractions were only temporary, and GTAs indicated they would return to the task causing the anxiety, it would be considered more adaptive than maladaptive. Among GTA participants, several types of activities such as exercise, watching TV, online shopping, or being with pets or friends, would distract them from their anxieties. For example, to cope with thinking about job security after graduation, Jack "push[es] it to the back of my brain as best I can ... I try to stay busy, exercise or go to the field. Those things to fight off those existential demons." However, determination of whether this in-between coping strategy was more adaptive or maladaptive was often difficult, because the outcome of the strategy was unknown.

\section{Helplessness (Maladaptive)}

Generally, compared with adaptive coping strategies, maladaptive strategies were reported less frequently by participants (Figure 1). However, among the maladaptive strategies mentioned, helplessness was the most commonly used, with seven GTAs employing this strategy toward teaching anxieties, and five GTAs for research anxieties. This coping strategy is characterized by the giving up or relinquishment of control. GTAs would often be at a loss for how to cope with their anxiety. For example, to manage anxiety related to not knowing the best practices in teaching, Laretta explained, "Well, when I'm in the classroom, unfortunately, I don't take steps to engage [with] the students. I kind of throw my hands up unfortunately; which is not the best thing to do." In research contexts, Reagan tried to cope with anxiety related to investing personal funds for her research: "I'll worry but it's not going to change anything." Or when Jack struggled with anxiety in keeping up with the literature, he explained, "It doesn't cause me to change my actions and fix it, it just lingers over me and it makes me feel bad." Most GTAs recognize the need to effectively cope with these anxieties; however, they are unsure what actions to take and eventually give up.

\section{Over Time GTAs Narrowed Their Use of Adaptive Coping Strategies}

When examining how participant coping strategies changed (were kept, abandoned, added, or never used) over time for both teaching and research, we found that many adaptive coping strategies were kept across both time points by GTAs, while 
(A) Teaching

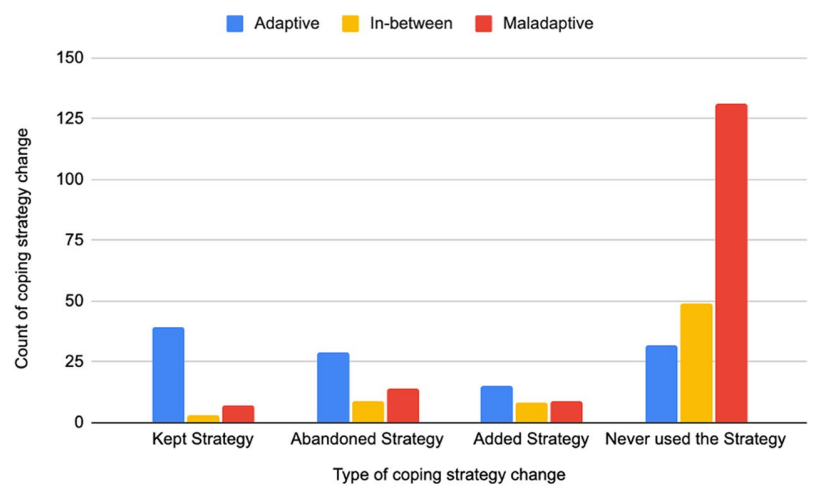

(B) Research

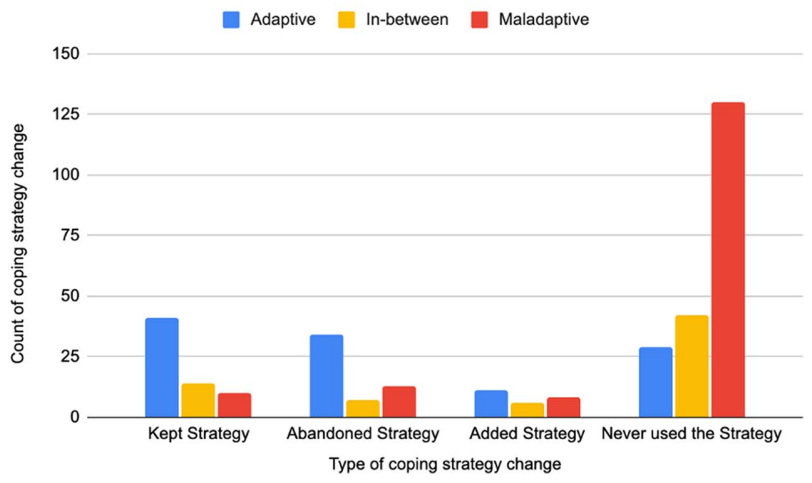

FIGURE 2. Count of the type of coping strategy change from 2016 to 2017 by biology GTAs in (A) teaching and (B) research contexts. Coping strategies are grouped into adaptive (blue), in-between (yellow), and maladaptive (red) strategies. "Count" refers to the number of coping strategies within each category (adaptive, in-between, maladaptive) that were classified as kept, abandoned, added, or never used for the entire GTA sample. Adaptive strategies were more likely to be kept over time for both teaching and research anxieties, while maladaptive strategies were never employed or abandoned.

maladaptive strategies were often never used or abandoned (Figure 2). Problem solving, for example, was used consistently to manage anxieties related to both teaching and research over time (Figure 3). Overall, however, more adaptive coping strategies were abandoned than kept or added in 2017, thus lowering the total use of different adaptive coping strategies over time. For instance, information seeking decreased in use from 2016 to 2017 , indicating that over time GTAs stopped looking for more information to cope with anxieties. On average, GTAs used approximately three adaptive strategies in 2016 and only about two strategies by 2017. For maladaptive strategies, there was generally less use of these strategies to begin with; therefore, most GTAs never used them, continued not to use them, or abandoned them in 2017. The individual participant results for coping strategies in 2016 and 2017 for teaching and research are shown in the Supplemental Tables 2-7.

\section{Changes in Coping to Teaching and Research Anxieties over Time}

For teaching anxieties specifically, the most dramatic decrease in coping strategy prevalence was with the use of adaptive coping
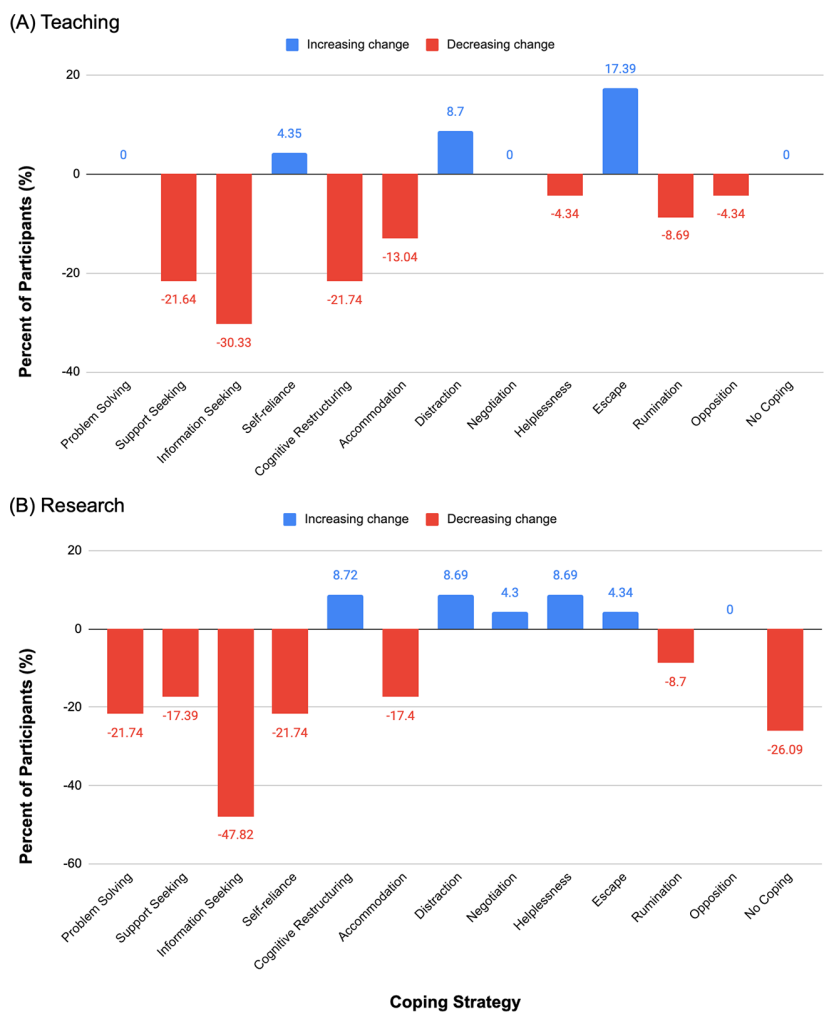

FIGURE 3. Change in coping strategies from 2016 and 2017 among 23 biology GTA participants for (A) teaching anxieties and (B) research anxieties. Blue bars indicate an increase in the use of that coping strategy from 2016 to 2017, while red bars indicate a decrease in that coping strategy used by participants from 2016 to 2017. The number above or below each bar is the change in percent emergence among the 23 biology GTAs for each strategy from 2016 to 2017.

mechanisms such as information seeking, support seeking, and cognitive restructuring (Figure 3). The use of information seeking had the greatest decrease within the participant population from 2016 to 2017. GTAs often employed information seeking when coping with anxieties related to not knowing the topic to be taught, not knowing the best pedagogies to use in the classroom, or not supporting students enough in their learning. We noticed that when those specific teaching anxieties did not emerge in 2017, information seeking was not present as well. However, when the same anxiety emerged in both years, and information seeking was not used in 2017, we found that the strategy had changed. For example, Emily used information seeking and problem solving in 2016 to tackle anxiety related to not knowing the best teaching practices to use in her classroom. In 2017, she used problem-solving coping based on the information she learned the previous year from a CIRTL workshop: "I'm trying to be more aware of [different teaching practices] ever since I took the firstlevel CIRTL." Between novice and experienced GTAs, there was no discernible pattern of keeping, abandoning, or adding this coping strategy (Supplemental Figure 1a and c). Notably, problem solving remained constant between 2016 and 2017.

We found similar trends in coping with research anxiety over time as compared with teaching (Figure 3). There tended to be a decrease in the use of adaptive coping, such as problem 
solving, support seeking, information seeking, and self-reliance from 2016 to 2017. Only two GTAs added support seeking as a strategy to manage teaching anxieties, while nine GTAs kept or added support seeking for research. No coping also notably decreased. As the name suggests, the category for no coping was characterized by GTAs who could not identify any coping strategies to mitigate anxiety or expressed feeling only some anxiety about a topic and did not need to cope. This lack of strategy is distinguished from helplessness, when individuals indicate a giving up or relinquishing control of a situation. For example, when Raj was asked how he coped with anxiety related to family pressure pushing him to graduate as soon as possible, he said: "I still haven't coped with it yet." Or when Mark identified anxiety related to not doing data analysis correctly, he said: "Yeah, for the most part it probably goes un-coped with." Over time, all five GTAs who did not have coping strategies in 2016 for research anxieties such as project commitment phobia or being evaluated by one's advisor had abandoned that category in 2017, suggesting that GTAs were finding strategies to use. Over time, novice and experienced GTAs kept or abandoned adaptive strategies toward research anxieties in similar ways (Supplemental Figure 1b and d).

\section{DISCUSSION}

Overall, biology GTAs demonstrated a greater use of adaptive coping strategies compared with maladaptive coping strategies in managing both teaching and research anxieties. When comparing coping with teaching and research anxieties, problem solving and information seeking were used for both roles, while support seeking, self-reliance, accommodation, and distraction were preferentially used for research anxieties, and cognitive restructuring for teaching anxieties. Over time, use of adaptive coping strategies decreased for both teaching and research anxieties; however, this was not associated with any increases in the use of maladaptive strategies. Individual GTAs, however, often swapped out the type of adaptive coping they used from year to year, suggesting that most had not reached stability in their coping strategies. These findings suggest that departments need to attend to GTA needs for teaching and research in different ways, regardless of GTA experience levels, given the differences in coping and shifts in strategies over time. Overall, providing GTAs with useful information sources, helping them develop supportive social networks, and providing emotional regulation strategies may be critical for graduate student mental health.

\section{Biology GTAs Primarily Used Adaptive Coping Strategies, but Maladaptive and In-Between Strategies Were Also Used}

Our findings about adaptive coping strategies being used most often by graduate students were consistent with previous work investigating other graduate student stressors (Kjerulff and Wiggins, 1976; Nelson et al., 2001; El-Ghoroury et al., 2012; Ickes et al., 2015; Nicklin et al., 2019). We posit that this may be true because GTAs have practiced using such strategies in managing anxieties during their undergraduate careers. For example, undergraduate students involved in course-based undergraduate research experiences, used mainly adaptive coping strategies such as problem solving, support seeking, and cognitive restructuring when managing failure or scientific obstacles in experimentation (Gin et al., 2018). Graduate stu- dents are a highly selective group and often did well in their undergraduate education. Studies on coping and academic success in college students have found that students who employed adaptive, problem-focused coping often had a higher GPAs (MacCann et al., 2011; Johnson and Michael Nussbaum, 2012). This suggests graduate students may enter their programs already having practiced some adaptive coping strategies.

GTA coping strategies were not universally adaptive, however. For teaching anxieties, GTA participants used helplessness, accommodation, and escape. These feelings of helplessness and cognitive acceptance (accommodation) of a teaching situation may be attributed to a combination of role tension (between teaching and other responsibilities), a lack of self-efficacy in teaching, especially for first-year GTAs, and the lack of autonomy in teaching (M.M.C.M., K.P., A.C., and E.E.S., unpublished data). These coping strategies suggest a feeling of being trapped and lacking support, indicating the need for ongoing teaching PD to help GTAs manage this important institutional role (Rushin et al., 1997; Prieto and Scheel, 2008; Schussler et al., 2015). These results partially supported our predictions that GTAs would use maladaptive coping strategies toward teaching anxieties; however, they did not use more maladaptive strategies for teaching compared with research. GTAs similarly employed coping strategies such as escape and helplessness toward research anxieties, also suggesting a feeling of not knowing what to do and needing to walk away from the problem. It is unknown whether these maladaptive strategies were ones that the GTAs also employed when they were undergraduates, or whether these were new coping strategies that emerged when they transitioned to graduate school.

\section{Problem Solving and Information Seeking Were Universally Useful Coping Strategies}

Problem solving and information seeking were the most-used strategies to manage both teaching and research anxieties. These were both active attempts to predict future problems and gather the information needed to control as much of the unknown as possible. Given that anxiety is a prospective emotion-an individual feels a lack of control about a potential occurrence-these are logical cognitive strategies to address this emotion. Often the GTAs were formulating a detailed plan or gathering more information from PD opportunities at the university. In our study, institutional instructional support programs such as CIRTL and in-house departmental funding workshops were reported as coping strategies aligned with information seeking or problem solving.

We posit that PD and similar resources help GTAs to build self-efficacy toward a task and increase their perceived control and thus contribute to adaptive coping (Lazarus and Folkman, 1984; Bandura, 1988; Betz and Hackett, 1997). An individual's choice of coping strategy has been found to be determined by that person's level of self-efficacy (Vandercleyen et al., 2014; Crego et al., 2016; Morales and Pérez-Mármol, 2019). Self-efficacy has been positively related to coping efficacy and effectiveness (e.g., Bandura, 1983, 1997; Bray, 2007). Bandura (1997) affirmed that self-efficacy expectations are a powerful resource for coping with stress and adjusting to stressful life conditions. Therefore, supporting the building of GTA self-efficacy may be an important focus for teaching and research roles in graduate school. 


\section{Certain Coping Strategies Were Used Preferentially to Manage Teaching or Research Anxieties}

Biology GTAs tended to use a greater diversity of coping strategies to manage research anxieties than teaching anxieties, employing self-reliance, accommodation, and distraction, but most especially support seeking. Considering the reported isolation that comes with being in graduate school (Ali and Gregg Kohun, 2006; Evans et al., 2018), the use of strategies like support seeking is unsurprising. Support seeking is critical for the socialization process of graduate students, often involving peers, friends, or family, but especially their advisors (Austin, 2003). Positive and close relationships between graduate students and their advisors often predict successful student outcomes, such as shorter time to degree, greater job satisfaction, and well-being (Ferrer De Valero, 2001; Beattie et al., 2006; Bagaka's et al., 2015; Sverdlik et al., 2018; German et al., 2019; Gin et al., 2021). GTAs often sought support from their personal and/or professional network when they needed reassurance about the quality of their work or emotional support to bolster their self-efficacy and perceived ability to cope (Jairam and Kahl, 2012).

GTAs may be employing more coping strategies for research simply because they are not familiar with how to successfully carry it out. In our experience, there is often less formal PD for research as compared with teaching, because science often relies on an apprenticeship model for the development of research skills (Flores, 2011). This explains why the advisor is such an important factor in graduate school success. Graduate students may also employ more coping strategies for research anxieties because of the perceived importance of research compared with teaching and the pressure they feel to be "productive" (Colbeck, 2008; Reid and Gardner, 2020). With 11 (47\%) of our GTA participants indicating academia as their first choice for a career, effectively coping with research anxieties may be seen as a litmus test to achieve those aspirations (Chang and Edwards, 2015). Thus, it may be that graduate students employ more of a quantity versus quality approach to their coping with research anxiety to achieve efficacy of coping. However, more data about frequency of coping is needed.

In teaching contexts, cognitive restructuring was a coping strategy used much more often than in research contexts. Individuals who employ cognitive restructuring try to take a stressor that is causing them unpleasantness and see it in a positive light. Besides concerns about the time teaching takes away from research, GTAs often lament the lack of autonomy in the classroom, which can cause anxiety (Kajfez and Matusovich, 2017; Winstone and Moore, 2017), something we found in this study as well. GTAs often implement a predetermined curriculum that may not be flexible or allow for GTA input. Cognitive restructuring may help GTAs reframe their teaching experiences to see the benefits of the tasks, despite their lack of autonomy.

\section{Over Time, Biology GTAs May Be Settling on More Specific Types of Adaptive Coping Strategies}

Over time, GTAs decreased their use of adaptive coping strategies in managing teaching and research anxieties. However, it appears that GTAs may simply be using a smaller subset of core coping approaches. For example, in our sample population, GTAs who previously used strategies such as problem solving, information seeking, or support seeking, often kept that strat- egy in the next year. GTAs may be employing only a few adaptive coping strategies after one year because they have identified the most effective coping approaches. Lazarus (1993) and Spencer et al. (1997) maintain that coping strategies often become increasingly stable over time, with a focus on only a few primary coping approaches. Graduate students, regardless of experience level, may be trying to reconcile their previous coping approaches as undergraduate students to determine the best coping strategies for graduate school tasks.

Stabilizing coping strategies over time may be related to improving task self-efficacy. When Chang and Edwards (2015) surveyed 314 nurses about self-efficacy, coping, and job satisfaction, they found that self-efficacy was positively associated with problem-focused coping styles and greater job satisfaction and negatively associated with emotion-focused, maladaptive coping. The influence of self-efficacy on job satisfaction was indirect and partially mediated by coping styles. Over time, as individuals socialize into their programs and are exposed to similar work tasks, mastery experiences will help them grow in self-efficacy and coping. However, graduate school is also a time of constantly shifting new tasks (data collection, data analysis, conference presentations, and manuscript writing occur simultaneously for multiple different research projects), and it may be that self-efficacy is hard to build for graduate school tasks when they are constantly shifting.

\section{Anxieties Related to Tension between Teaching and Research Roles May Need to be Further Considered}

This study was not able to assess the efficacy of the adaptive coping that GTAs used, and one question we ask is if GTAs use mostly adaptive coping strategies, why is there a burgeoning mental health crisis among graduate students? Exploring GTA coping to teaching and research roles is only a first step in helping address this question. Along with teaching and research anxiety, other stressors such as academic responsibilities, finances, and poor work-life balance have been reported by graduate students (El-Ghoroury et al., 2012). Moreover, the tension between professional roles may also contribute to the mental health stressors of a graduate student (Connolly et al., 2016). The dichotomy between teaching and research has been perceived as roles that are at odds in academia (Colbeck, 2008; Brownell and Tanner, 2012; Pan et al., 2014; Reid and Gardner, 2020). Time spent on teaching is time not spent on research, and many graduate students feel the pressures of these time constraints themselves, or sometimes even imposed and messaged by their advisors (Gottlieb and Keith, 1997; Lane et al., 2019). However, more recently, evidence has shown that research and teaching are not in conflict (Shortlidge and Eddy, 2018) and can be viewed synergistically (Reid and Gardner, 2020). Perhaps GTAs who hold a hybrid identity between these roles (as teacher and researcher) may be better able to negotiate tensions that arise between them. The extent to which anxieties and coping are related to the tensions between teaching and research roles is an area that needs to be further explored.

\section{Limitations}

Our study identified the types of coping strategies biology GTAs employed to regulate anxieties related to teaching and research roles; however, we did not measure the efficacy of such coping. It may be that particular coping strategies are more effective at 
reducing anxieties compared with other coping strategies. For example, support seeking through positive mentoring from a doctoral advisor is often a critical component in measuring graduate student success and may be more efficacious compared with self-reliance. Future studies should consider how to best measure coping efficacy through collecting self-reported quantitative or qualitative metrics of student performance (e.g., research publications, conference presentations, teaching evaluations) or career outcomes.

Another limitation lies in the nature of discussing a stigmatized topic. The open-ended interview format of this study often allowed for intimacy between the participants and the interviewer. However, factors such as social desirability may have led participants to avoid talking about maladaptive coping strategies to avoid judgment. Though we ensured full confidentiality, it may be difficult to avoid the social desirability of coping adaptively. Also, our approach assumes participants have reflected, remembered, and are cognizant of the way they cope with certain anxieties, which may not always be the case.

Finally, we recognize that coping is situational, developmental, and culturally bound. We acknowledge that different subpopulations of graduate students may cope in unique ways in response to the same stressor. Notably, the number of women in the interview pool is greater than the survey pool. Some literature suggests gender differences in coping between men and women; with women's coping style being more emotion focused and less problem centered than that of the men (Matud, 2004). This may be a contributing factor as to why women suffer more somatic symptoms and psychological distress than the men. Future research would benefit from investigation of differences in coping between subpopulations of graduate students.

\section{Recommendations for Supporting Graduate Student Coping with Teaching and Research Anxieties}

Coping with Teaching Anxiety. Despite increasing opportunities for teaching PD for graduate students (Rushin et al., 1997; Schussler et al., 2015), many GTAs still perceive an institutional lack of support for teaching-related PD (Goodwin et al., 2018). As our GTAs mentioned in the study, access to PD and similar resources supported their information-seeking and problem-solving coping strategies. PD positively impacts the teaching self-efficacy of GTAs (Connolly et al., 2018; Reeves et al., 2018) and can therefore lead to the development of adaptive coping strategies. Greater awareness and advocacy for teaching PD opportunities on the part of graduate programs and faculty can help connect more graduate students to those resources.

Coping with Research Anxiety. Departments and institutions should consider how they create opportunities for graduate students to build social support. Biology GTAs overwhelmingly spoke about reaching out to their networks (e.g., academic friends, family, advisors) for emotional and professional support. The literature also suggests that having genuine support is instrumental for graduate students to successfully navigate program stressors and ultimately graduate (Jairam and Kahl, 2012; Hunter and Devine, 2016). This genuine support should ideally come from their mentoring faculty member, as that relationship often predicts a graduate student's persistence in academia and reduced emotional exhaustion (Hunter and
Devine, 2016). Given our findings that coping strategies change over time, faculty mentors need to regularly check in with their graduate students to offer new advice, coping strategies, and institutional resources as they progress through their programs. Further, graduate students are encouraged to band together and form social groups within departmental units, where they can share knowledge about the program (information seeking), create action plans (problem solving), or just empathize over shared stressors (support seeking). Such groups can also organize larger events to further support the graduate student community, such as mental health forums or career panel workshops (Mousavi et al., 2018). Additionally, graduate programs and advisors should allow graduate students to have an active and collaborative voice to proactively engage in practices or activities that support holistic research training and diverse career outcomes (NASEM, 2018). Not all graduate students want to pursue academic careers, and programs need to support transferable skills for other career paths of interest to students.

\section{Conclusions}

Graduate school is a time when students learn to balance multiple roles, such as teaching and research, and distinct anxieties often emerge as students navigate these roles. Using the appropriate coping strategies to regulate these anxieties is important to maintain positive mental health and career intentions. This study sought to capture the major coping strategies used to mitigate teaching and research anxieties and identified that most coping strategies used by biology GTAs were adaptive in nature and distinct between professional roles. Our study suggests that resources on coping strategies such as problem solving, information seeking, and support seeking may be helpful to graduate students at all levels of the program. Learning to cope effectively with teaching and research anxieties may therefore help to reduce attrition in graduate programs and address the epidemic of mental health concerns that graduate students are currently experiencing.

\section{ACKNOWLEDGMENTS}

Thank you to Caroline Wienhold, Maryrose Weatherton, Randall Small, Sarah Andrews, Nicole Chodkowski, Robert Furrow, Brie Tripp, Lisa Corwin, and the REACH Lab for their comments on earlier versions of the paper. Thank you to the Ecology and Evolutionary Department at UT Knoxville for providing research funds to support our incentives. Funding for open access to this research was also generously provided by University of Tennessee's Open Publishing Support Fund. Finally, thank you to all GTA participants for taking part in this research.

\section{REFERENCES}

Ali, A., \& Gregg Kohun, F. (2006). Dealing with isolation feelings in IS doctoral programs. International Journal of Doctoral Studies, 1, 021-033. https://doi.org/10.28945/58

Austin, A. E. (2002). Preparing the next generation of faculty. Journal of HigherEducation, 73(1), 94-122. https://doi.org/10.1080/00221546.2002 .11777132

Austin, A. E. (2003). Creating a bridge to the future: Preparing new faculty to face changing expectations in a shifting context. Review of Higher Education, 26(2), 119-144. https://doi.org/10.1353/rhe.2002.0031

Austin, A. E., \& Wulff, D. H. (2004). The challenge to prepare the next generation of faculty. In Wulff, D. H., \& Austin, A. E. (Eds.), Paths to the 
professoriate: Strategies for enriching the preparation of future faculty (pp. 3-16). San Francisco, CA: Jossey Bass.

Bagaka's, J. G., Badillo, N., Bransteter, I., \& Rispinto, S. (2015). Exploring student success in a doctoral program: The power of mentorship and research engagement. International Journal of Doctoral Studies, 10, 323 342. https://doi.org/10.28945/2291

Bandura, A. (1983). Self-efficacy determinants of anticipated fears and calamities. Journal of Personality and Social Psychology, 45(2), 464-469. https://doi.org/10.1037/0022-3514.45.2.464

Bandura, A. (1988). Self-efficacy conception of anxiety. Anxiety Research, 7(1), 77-98. https://doi.org/https://doi.org/10.1080/10615808808248222

Bandura, A. (1997). Self-efficacy: The exercise of control. New York: Freeman/Times Books/Henry Holt.

Barsky, A. J., Peekna, H. M., \& Borus, J. F. (2001). Somatic symptom reporting in women and men. Journal of general internal medicine, 16(4), $266-$ 275.

Beattie, G., \& Shovelton, H., Blindern, P. O., Duit, R., Treagust, D., Givry, D., ... \& Driver, R. (2006). An experimental investigation of some properties of individual iconic ... Cognition, 43(2), 1086-1109. https://doi.org/10.1002/tea

Betz, N. E., \& Hackett, G. (1997). Applications of self-efficacy theory to the career assessment of women. Journal of Career Assessment, 5(4), 383402. https://doi.org/10.1177/106907279700500402

Blake, C. E., Bisogni, C. A., Sobal, J., Devine, C. M., \& Jastran, M. (2007) Classifying foods in contexts: How adults categorize foods for different eating settings. Appetite, 49(2), 500-510. https://doi.org/10.1016/ j.appet.2007.03.009

Bray, S. R. (2007). Self-efficacy for coping with barriers helps students stay physically active during transition to their first year at a university. Research Quarterly for Exercise and Sport, 78(2), 61-70. https://doi.org/ 10.1080/02701367.2007.10599404

Brownell, S. E., \& Tanner, K. D. (2012). Barriers to faculty pedagogical change: Lack of training, time, incentives, and ... tensions with professional identity? CBE-Life Sciences Education, 11(4), 339-346. https://doi.org/ 10.1187/cbe.12-09-0163

Burla, L., Knierim, B., Barth, J., Liewald, K., Duetz, M., \& Abel, T. (2008). From text to codings: Intercoder reliability assessment in qualitative content analysis. Nursing Research, 57(2), 113-117. https://doi.org/10.1097/01.NNR $.0000313482 .33917 .7 d$

Carver, C., Scheier, M., \& Weintraub, J. (1989). Assessing coping strategies: A theoretically based approach. Journal of Personality and Social Psychology, 56(2), 257-283.

Chang, Y., \& Edwards, J. K. (2015). Examining the relationships among self-efficacy, coping, and job satisfaction using social career cognitive theory: An SEM analysis. Journal of Career Assessment, 23(1), 35-47. https://doi.org/10.1177/1069072714523083

Charmaz, K. (2006). Constructing grounded theory: A practical guide through qualitative analysis. Thousand Oaks, CA: Sage.

Colbeck, C. L. (2008). Professional identity development theory and doctoral education. New Directions for Teaching and Learning, 2008(113), 916. https://doi.org/10.1002/tl.304

Connolly, M. R., Lee, Y. G., \& Savoy, J. N. (2018). The effects of doctoral teaching development on early-career STEM scholars' college teaching self-efficacy. CBE-Life Sciences Education, 17(1), 1-15. https://doi .org/10.1187/cbe.17-02-0039

Connolly, M. R., Savoy, J. N., Lee, Y., \& Hill, L. B. (2016). Building a better future STEM faculty: How teaching development programs can improve undergraduate education. Madison, WI: Wisconsin Center for Education Research, University of Wisconsin-Madison.

Conrad, L. Y., \& Tucker, V. M. (2019). Making it tangible: Hybrid card sorting within qualitative interviews. Journal of Documentation, 75(2), 397-416. https://doi.org/10.1108/JD-06-2018-0091

Crego, A., Carrillo-Diaz, M., Armfield, J. M., \& Romero, M. (2016). Stress and academic performance in dental students: The role of coping strategies and examination-related self-efficacy. Journal of Dental Education, 80(2), 165-172. https://doi.org/10.1002/j.0022-0337.2016.80.2.tb06072.x

Edward, K. L., \& Warelow, P. (2005). Resilience: When coping is emotionally intelligent. Journal of the American Psychiatric Nurses Association, 11(2), 101-102. https://doi.org/10.1177/1078390305277526
El-Ghoroury, N. H., Galper, D. I., Sawaqdeh, A., \& Bufka, L. F. (2012). Stress, coping, and barriers to wellness among psychology graduate students. Training and Education in Professional Psychology, 6(2), 122-134. https://doi.org/10.1037/a0028768

Evans, T. M., Bira, L., Gastelum, J. B., Weiss, L. T., \& Vanderford, N. L. (2018). Evidence for a mental health crisis in graduate education. Nature Biotechnology, 36(3), 282-284. https://doi.org/10.1038/nbt.4089

Ferrer De Valero, Y. (2001). Departmental factors affecting time-to-degree and completion rates of doctoral students at one Land-Grant research institution. Journal of Higher Education, 72(3), 341-367. https://doi. org/10.2307/2649335

Flick, U. (2014). An introduction to qualitative research (5th ed.). Thousand Oaks, CA: Sage.

Flores, E. M. (2011). Becoming a researcher: A qualitative study of the apprenticeship model in doctoral education. Seattle: University of Washington.

Folkman, S., Lazarus, R. S., Dunkel-Schetter, C., DeLongis, A., \& Gruen, R. J. (1986). Dynamics of a stressful encounter. Cognitive appraisal, coping, and encounter outcomes. Journal of Personality and Social Psychology. 50(5), 992-1003. https://doi.org/10.1037/0022-3514.50.5.992

Fuhrmann, C. N., Halme, D. G., O'Sullivan, P. S., \& Lindstaedt, B. (2011). Improving graduate education to support a branching career pipeline: Recommendations based on a survey of doctoral students in the basic biomedical sciences. CBE-Life Sciences Education, 10(3), 239-249. https:// doi.org/10.1187/cbe.11-02-0013

German, K. T., Sweeny, K., \& Robbins, M. L. (2019). Investigating the role of the faculty advisor in doctoral students' career trajectories. Professional Development in Education, 45(5), 762-773. https://doi.org/10.1080/ 19415257.2018.1511454

Gin, L. E., Rowland, A. A., Steinwand, B., Bruno, J., \& Corwin, L. A. (2018). Students who fail to achieve predefined research goals may still experience many positive outcomes as a result of CURE participation. CBE-Life Sciences Education, 17(4), ar57. https://doi.org/10.1187/cbe.18-03-0036

Gin, L. E., Wiesenthal, N. J., Ferreira, I., \& Cooper, K. M. (2021). PhDepression: Examining how graduate research and teaching affect depression in life sciences PhD students. CBE-Life Sciences Education, 20(3), ar41. https://doi.org/10.1187/cbe.21-03-0077

Gintner, G. G., West, J. D., \& Zarski, J. J. (1989). Learned resourcefulness and situation-specific coping with stress. The Journal of Psychology, 123(3), 295-304. https://doi.org/10.1080/00223980.1989.10542985

Glaser, B., \& Strauss, A. (1967). The Discovery of Grounded Theory: Strategies for Qualitative Research. Mill Valley, CA: Sociology Press.

Golde, C. M. (2005). The role of the department and discipline in doctoral student attrition: Lessons from four departments. Journal of Higher Education, 76(6), 669-700. https://doi.org/10.1353/jhe.2005.0039

Goodwin, E. C., Cao, J. N., Fletcher, M., Flaiban, J. L., \& Shortlidge, E. E. (2018). Catching the wave: Are biology graduate students on board with evidence-based teaching? CBE-Life Sciences Education, 17(3), 1-13. https://doi.org/10.1187/cbe.17-12-0281

Gottlieb, E. E., \& Keith, B. (1997). The academic research-teaching nexus in eight advanced-industrialized countries. Higher Education, 34(3), 397419.

Hayes, J. R., \& Hatch, J. A. (1999). Issues in measuring reliability correlation versus percentage of agreement. Written Communication, 16(3), $354-$ 367. https://doi.org/10.1177/0741088399016003004

Henry, M. A., Shorter, S., Charkoudian, L., \& Heemstra, J. M. (2019). FAIL is not a four-letter word: A theoretical framework for exploring undergraduate students' approaches to academic challenge and responses to failure in STEM learning environments. CBE-Life Sciences Education, 18(1), ar11. https://doi.org/10.1187/cbe.18-06-0108

Horowitz, S. V., Boardman, S. K., \& Redlener, I. (1994). Constructive conflict management and coping in homeless children and adolescents. Journal of Social Issues, 50(1), 85-98. https://doi.org/10.1111/j.1540-4560.1994 tb02399.x

Hunter, K. H., \& Devine, K. (2016). Doctoral students' emotional exhaustion and intentions to leave academia. International Journal of Doctoral Studies, 11, 35-61.

Ickes, M. J., Brown, J., Reeves, B., \& Zephyr, P. M. D. (2015). Differences between undergraduate and graduate students in stress and coping 
strategies. Californian Journal of Health Promotion, 13(1), 13-25. https:// doi.org/10.32398/cjhp.v13i1.1810

Jairam, D., \& Kahl, D. H. (2012). Navigating the doctoral experience: The role of social support in successful degree completion. International Journal of Doctoral Studies, 7, 311-329. https://doi.org/10.28945/1700

Johnson, M. L., \& Michael Nussbaum, E. (2012). Achievement goals and coping strategies: Identifying the traditional/nontraditional students who use them. Journal of College Student Development, 53(1), 41-54. https:// doi.org/10.1353/csd.2012.0002

Kajfez, R. L., \& Matusovich, H. M. (2017). Competence, autonomy, and relatedness as motivators of graduate teaching assistants. Journal of Engineering Education, 106(2), 245-272. https://doi.org/10.1002/jee.20167

Kajfez, R. L., \& McNair, L. D. (2014). Graduate student identity: A balancing act between roles. Paper presented at the 121st American Society for Engineering Education (ASEE) Annual Conference \& Exposition. June 14-16. (Ed.), 121st ASEE Annual Conference \& Exposition (pp. 1-16). Indianapolis, IN. https:/doi.org/10.18260/1-2-20543

Kjerulff, K., \& Wiggins, N. H. (1976). Graduate student styles for coping with stressful situations. Journal of Educational Psychology, 68(3), 247-254. https://doi.org/10.1037/0022-0663.68.3.247

Krippendorff, K. (2004). Reliability in content analysis. Human Communication Research, 30(3), 411-433. https://doi.org/10.1111/j.1468-2958.2004. tb00738.x

Landis, J. R., \& Koch, G. G. (1977). The Measurement of observer agreement forcategoricaldata. Biometrics, 33(1),159. https://doi.org/10.2307/2529310

Lane, A. K., Hardison, C., Simon, A., \& Andrews, T. C. (2019). A model of the factors influencing teaching identity among life sciences doctoral students. Journal of Research in Science Teaching, 56(2), 141-162. https:// doi.org/10.1002/tea.21473

Lashuel, H. A. (2020). Mental health in academia: What about faculty? ELife, 9, 9-11. https://doi.org/10.7554/eLife.54551

Lazarus, R. (1993). Coping theory and research: Past, present, and future. Psychosomatic Medicine, 55(3), 234-247. https://doi.org/10.1097/00006842 -199305000-00002

Lazarus, R., \& Folkman, S. (1984). Stress, appraisal, and coping. New York: Springer.

LeBreton, J. M., \& Senter, J. L. (2008). Answers to 20 questions about interrater reliability and interrater agreement. Organizational Research Methods, 11(4), 815-852. https://doi.org/10.1177/1094428106296642

Lent, R. W., Brown, S. D., \& Hackett, G. (1994). Toward a unifying social cognitive theory of career and academic interest, choice, and performance. Journal of vocational behavior, 45(1), 79-122.

Levecque, K., Anseel, F., De Beuckelaer, A., Van der Heyden, J., \& Gisle, L. (2017) Work organization and mental health problems in PhD students. Research Policy, 46(4), 868-879. https://doi.org/10.1016/j.respol.2017.02.008

MacCann, C., Fogarty, G. J., Zeidner, M., \& Roberts, R. D. (2011). Coping mediates the relationship between emotional intelligence (EI) and academic achievement. Contemporary Educational Psychology, 36(1), 60-70. https://doi.org/10.1016/j.cedpsych.2010.11.002

Mackie, S. A., \& Bates, G. W. (2019). Contribution of the doctoral education environment to $\mathrm{PhD}$ candidates' mental health problems: A scoping review. Higher Education Research \& Development, 38(3), 565-578.

Matud, M. P. (2004). Gender differences in stress and coping styles. Personality and Individual Differences, 37(7), 1401-1415. https://doi. org/10.1016/j.paid.2004.01.010

Morales, F. M., \& Pérez-Mármol, J. M. (2019). The role of anxiety, coping strategies and emotional intelligence on general perceived self-efficacy in university students. Frontiers in Psychology, 10, 1689. https://doi .org/10.3389/fpsyg.2019.01689

Mousavi, M. P. S., Sohrabpour, Z., Anderson, E. L., Stemig-vindedahl, A., Golden, D., Christenson, G., ... \& Bu, P. (2018). Stress and mental health in graduate school: How student empowerment creates lasting change. Journal of Chemical Education, 95(11), 1939-1946. https://doi.org/ 10.1021/acs.jchemed.8b00188

Nagy, G. A., Fang, C. M., Hish, A. J., Kelly, L., Nicchitta, C. V., Dzirasa, K., \& Rosenthal, M. Z. (2019). Burnout and mental health problems in biomedical doctoral students. CBE-Life Sciences Education, 18(2), ar27. https:// doi.org/10.1187/cbe.18-09-0198
National Academies of Sciences Engineering and Medicine. (2018). Graduate STEM education for the 21st century. Washington, DC: National Academies Press. https://doi.org/10.17226/25038

Nelson, N. G., Dell'Oliver, C., Koch, C., \& Buckler, R. (2001). Stress, coping and success among graduate students in clinical psychology. Psychological Reports, 88(3), 759-767. https://doi.org/10.2466/pr0.2001.88.3.759

Nicklin, J. M., Meachon, E. J., \& McNall, L. A. (2019). Balancing work, school, and personal life among graduate students: A positive psychology approach. Applied Research in Quality of Life, 14(5), 1265-1286. https://doi org/10.1007/s11482-018-9650-z

Organisation for Economic Co-operation and Development [OECD]. (2014) Who are the doctorate holders and where do their qualifications lead them? Education Indicators in Focus, 25, 1-4. https://doi.org/10.1787/ 5jxv8xsvp1g2-en

Pan, W., Cotton, D., \& Murray, P. (2014). Linking research and teaching: Context, conflict and complementarity. Innovations in Education and Teaching International, 51(1), 3-14. https://doi.org/10.1080/14703297 .2013.847794

Prieto, L. R., \& Scheel, K. R. (2008). Teaching assistant training in counseling psychology. Counselling Psychology Quarterly, 21(1), 49-59. https://doi org/10.1080/09515070801900780

Reeves, T. D., Hake, L. E., Chen, X., Frederick, J., Rudenga, K., Ludlow, L. H., \& O'Connor, C. M. (2018). Does context matter? Convergent and divergent findings in the cross-institutional evaluation of graduate teaching assistant professional development programs. CBE-Life Sciences Education 17(1), 1-13. https://doi.org/10.1187/cbe.17-03-0044

Reid, J. W., \& Gardner, G. E. (2020). Navigating tensions of research and teaching: Biology graduate students' perceptions of the researchteaching nexus within ecological contexts. CBE-Life Sciences Education, 19(3), 1-16. https://doi.org/10.1187/cbe.19-11-0218

Roth, S., \& Cohen, L. J. (1986). Approach, avoidance, and coping with stress. American Psychologist, 41(7), 813. https://doi.org/10.1037/0003 $-066 \times .41 .7 .813$

Rummell, C. M. (2015). Professional psychology: Research and practice an exploratory study of psychology graduate student workload, health, and program satisfaction an exploratory study of psychology graduate student workload, health, and program satisfaction. Professional Psychology: Research and Practice, 46(6), 391-399. https://doi.org/10.1037/ pro0000056

Rushin, J. W., De Saix, J., Lumsden, A., Streubel, D. P., Summers, G., \& Bernson, C. (1997). Graduate teaching assistant training: A basis for improvement of college biology teaching \& faculty development? American Biology Teacher, 59(2), 86-90.

Saldaña, J. (2012). The coding manual for qualitative researchers. Thousand Oaks, CA: Sage.

Schussler, E. E., Read, Q., Marbach-Ad, G., Miller, K., \& Ferzli, M. (2015). Preparing biology graduate teaching assistants for their roles as instructors: An assessment of institutional approaches. CBE-Life Sciences Education, 14(3), 1-11. https://doi.org/10.1187/cbe-14-11 $-0196$

Schwandt, T. (2007). Thematic analysis. In The Sage dictionary of qualitative inquiry. https://doi.org/10.4135/9781412986281

Shin, H., Park, Y. M., Ying, J. Y., Kim, B., Noh, H., \& Lee, S. M. (2014). Relationships between coping strategies and burnout symptoms: A meta-analytic approach. Professional Psychology: Research and Practice, 45(1), 44-56. https://doi.org/10.1037/a0035220

Shortlidge, E. E., \& Eddy, S. L. (2018). The trade-off between graduate student research and teaching: A myth? PLOS ONE, 13(6), 4-6. https://doi .org/10.1371/journal.pone.0199576

Skinner, E. A., Edge, K., Altman, J., \& Sherwood, H. (2003). Searching for the structure of coping: A review and critique of category systems for classifying ways of coping. Psychological Bulletin, 129(2), 216-269. https:// doi.org/10.1037/0033-2909.129.2.216

Spencer, M. B., Dupree, D., \& Hartmann, T. (1997). A phenomenological variant of ecological systems theory (PVEST): A self-organization perspective in context. Development and Psychopathology, 9(4), 817-833. https://doi.org/10.1017/S0954579497001454

Spradley, J. P. (1979). The ethnographic interview. New York: Holt, Rinehart and Winston. 
Stemler, S. E. (2004). A comparison of consensus, consistency, and measurement approaches to estimating interrater reliability. Practical Assessment, Research, and Evaluation, 9(1), 4. https://doi.org/10.7275/ 96jp-xzO7

Strauss, A., \& Corbin, J. (2008). Basics of qualitative research: techniques and procedures for developing grounded theory (3rd ed.). Thousand Oaks, CA: Sage. https://doi.org/10.4135/9781452230153

Corbin, J., \& Strauss, A. (2008). Basics of qualitative research (3rd ed.): Techniques and procedures for developing grounded theory. SAGE Publications, Inc.

Sundberg, M. D., Armstrong, J. E., \& Wischusen, E. W. (2005). A reappraisal of the status of introductory biology laboratory education in U.S. colleges $\&$ universities. American Biology Teacher, 67(9), 525-529. https://doi.org/ 10.1662/0002-7685(2005)067[0525:AROTSO]2.0.CO;2

Sverdlik, A., Hall, N. C., McAlpine, L., \& Hubbard, K. (2018). The PhD experience: A review of the factors influencing doctoral students' completion, achievement, and well-being. International Journal of Doctoral Studies, 13, 361-388. https://doi.org/10.28945/4113
Van Maanen, J. (1976). Breaking in: Socialization to work. In Dubin, R. (Ed.), Handbook of Work, Organization and Society (pp. 67-130). Chicago, IL: Rand McNally College Publishing Co.

Vandercleyen, F., Boudreau, P., Carlier, G., \& Delens, C. (2014). Pre-service teachers in PE involved in an organizational critical incident: Emotions, appraisal and coping strategies. Physical Education and Sport Pedagogy, 19(2), 164-178. https://doi.org/10.1080/17408989.2012 .732564

Weller, S. C., \& Romney, A. K. (1988). Systematic data collection. Los Angeles: Sage.

White, M. D., \& Marsh, E. E. (2006). Content analysis: A flexible methodology Library Trends, 55(1), 22-45. https://doi.org/10.1353/lib.2006.0053

Winstone, N., \& Moore, D. (2017). Sometimes fish, sometimes fowl? Liminality, identity work and identity malleability in graduate teaching assistants. Innovations in Education and Teaching International, 54(5), 494-502. https://doi.org/10.1080/14703297.2016.1194769

Woolston, C. (2019). PhD poll reveals fear and joy, contentment and anguish. Nature, 575, 403-406. https://doi.org/10.1038/d41586-019-03459-7 